Historias cruzadas en noches oscuras: acercamiento crítico a la película cubana Chamaco (2010) de Juan Carlos Cremata

Cross Stories in Dark Nights: Critical Approach to the Cuban Film Chamaco (2010) by Juan Carlos Cremata

Dayron De León Castillo

Leonardo Gell Fernández-Cueto 


\title{
Historias cruzadas en noches oscuras: acercamiento crítico a la película cubana Chamaco (2010) de Juan Carlos Cremata
}

\section{Cross Stories in Dark Nights: Critical Approach to the Cuban Film Chamaco (2010) by Juan Carlos Cremata}

\author{
Dayron De León Castillo' \\ Universidad de Costa Rica \\ San José, Costa Rica \\ Leonardo Gell Fernández-Cueto² \\ Universidad de Costa Rica \\ San José, Costa Rica
}

Recibido: 24 de diciembre de 2019 Aprobado: 2 de junio de 2020

\begin{abstract}
Resumen
Este artículo se propone realizar un análisis crítico acerca de la película cubana Chamaco (2010) del director Juan Carlos Cremata (n. 1961), basada en la obra teatral homónima de Abel González Melo (n. 1980). Las preguntas que lo originan pretenden evidenciar los temas sociales que Chamaco introduce a la cinematografía cubana -con énfasis en lo concerniente a la construcción de la sexualidad masculina-, cómo maneja su director los códigos cinematográficos a partir de un texto teatral, qué realidades del entramado social aborda y desde qué perspectiva lo hace. Para ello, los autores se apoyan en publicaciones

1 Estudiante egresado de la Maestría Centroamericana en Sociología, Universidad de Costa Rica (UCR). Licenciado en Sociología, Universidad de La Habana, Cuba. ORCID. 0000-0002-5697-7094. Correo electrónico: dayrondeleoncastillo@gmail.com

2 Docente de la Escuela de Artes Musicales, del Posgrado en Artes e investigador del Instituto de Investigaciones en Arte de la UCR. Doctorando del Programa de Doctorado en Estudios de la Sociedad y la Cultura de la UCR. Máster en Música con énfasis en Piano, Universidad de Costa Rica. ORCID: 0000-0002-6572-112X. Correo electrónico: leonardo.gell_f@ucr.ac.cr
\end{abstract}


referentes a ambas obras dramáticas, a aspectos históricos de la industria cubana del cine, el cine queer, así como aspectos sobre la construcción de sentidos desde la imagen.

Palabras clave: cine; Cuba; estereotipo sexual; comportamiento sexual; grupo sexual minoritario

\begin{abstract}
This article proposes to carry out a critical analysis about the Cuban film Chamaco (2010) by the director Juan Carlos Cremata (b. 1961), based on the homonymous play by Abel González Melo (b. 1980). The questions that originate it are intended to show the social issues that Chamaco introduces to Cuban cinematography -with emphasis on the construction of male sexuality-, how its director handles cinematographic codes from a theatrical text, what realities of the framework social approach and from what perspective does it. For this, the authors rely on publications referring to both dramatic works, historical aspects of the Cuban film industry, queer cinema, as well as aspects of the construction of meanings from the image.
\end{abstract}

Keywords: cinema; Cuba; gender stereotypes; sexual behaviour; gender minorities 
Historias cruzadas en noches oscuras: acercamiento crítico

Artículo

a la película cubana Chamaco (2010) de Juan Carlos Cremata

\section{Introducción}

La impronta del cine cubano en la historia de la cinematografía iberoamericana es un hecho ineludible, si hacemos un repaso de lo acontecido en los últimos 60 años de creación en el celuloide. La producción de cine en la isla ha dejado una extensa lista de títulos que son referentes estético-discursivos y dan cuenta de la evolución de la industria en la región, a lo largo de las últimas décadas. Más allá del reconocimiento a filmes en particular, en su paso por festivales y muestras internacionales, la industria cubana destaca por el fomento de una nueva perspectiva, un nuevo modo de hacer y ver el cine en su dimensión sociopolítica. Durante estos años, varios filmes -en los más diversos formatos y géneros- constituyen objeto de estudio en academias, bien por el manejo de narrativas desmarcadas del cine comercial, el quiebre temático, la introducción de nuevas voces y protagonistas, así como por el estrecho vínculo entre creación e ideología.

Con el triunfo revolucionario, el 1 de enero de 1959, sobrevino en Cuba un proceso radical y acelerado de transformaciones en el entramado social, cultural, político e institucional del país, en el que prevaleció la abierta intensión de desmontar estructuras del pasado para la construcción de un nuevo modelo de sociedad. La dirección del país comprendió, desde el inicio, que los cambios tenían que acontecer también desde el arte y la cultura, en tanto catalizadores de la conciencia colectiva. Es así que la naciente revolución se volcó a la creación de instituciones que fomentaran y canalizaran el quehacer artístico, no solo como estructuras para acoger el torrente creativo que suscitó la nueva promesa de sociedad, sino también como una poderosa herramienta de propaganda ideológica estatal.

Luego de la creación del Instituto Cubano del Arte e Industria Cinematográficos $(\mathrm{ICAIC})^{3}$ transcurre un período definido como el momento de fundación y época de oro de la industria cinematográfica nacional, el cual se extiende durante la década de 1960. Es característico de esta etapa la producción de un cine convocado al reflejo de las profundas transformaciones que sucedían en el país, la épica revolucionaria y al desanclaje de estructuras y prácticas del pasado, en las cuales aspectos preteridos de la política y la sociedad (en suma, la cultura) comienzan a ser vistos desde una perspectiva crítica. La nueva institución gubernamental tenía en sus manos la tarea de incidir en la subjetividad colectiva, conformar la sociedad naciente y desarticular la colonización mental a la que

3 La Ley 169 del Gobierno Revolucionario, publicada el 24 de marzo de 1959 en La Gaceta Oficial, permitió la fundación del Instituto Cubano del Arte e Industria Cinematográficos (Álvarez, 2016, p. 107).

ESCENA. Revista de las artes, 2021, Vol. 81, Núm. 1 (julio-diciembre), pp. 183-206 
habían sido sometidos en el pasado (Álvarez, 2016). De acuerdo con Álvarez (2016), "al finalizar la etapa 1959-1969 el cine había devenido en un básico instrumento subversor del pasado y creador del presente" (p. 93).

Aunque no podemos homogeneizar las características de este período fundacional, vasto y renovador, es necesario anotar como rasgo común la alineación política de la producción cinematográfica con el proceso revolucionario. Esto, en buena medida, dado porque, para ese momento -y hasta finales de la década de 1980-, el cine cubano se realizaba fundamentalmente en el marco institucional del ICAIC. El cine independiente encontró entonces dificultades con la producción centralizada desde el ICAIC, que mantuvo a la creación alternativa sin acceso a espacios, recursos, ni plataforma que permitieran su emergencia y desarrollo (Ramos, 2013).

Hasta la década de 1980, el cine institucionalizado continuó recreando el acontecer, las dinámicas y procesos de la isla, pero con cambios temáticos, acordes a la compleja realidad nacional y la emergencia de problemáticas derivadas del nuevo orden social que se abría paso. Con la llegada del llamado período especial ${ }^{5}$ se marcó un punto de quiebre en los derroteros de la creación y el papel centralizadador del ICAIC sobre la producción nacional. Si bien con anterioridad habían sido soslayados determinados tópicos que resultaban "incómodos" o eran interpretados como contravención a la línea política de la revolución, la industria del cine comienza a transformarse. Emerge entonces un cine que se desmarca del devenir institucional, tocado por los efectos sociales de la crisis sobre el pueblo de Cuba, donde las carencias materiales marginalizaron a amplios sectores. Aparecen así varios filmes, cuyos argumentos connotaban realidades que, aunque antes eran latentes, para ese momento cobraron un protagonismo sin precedentes.

4 Álvarez (2016) realiza un recorrido sucinto por la cinematografía cubana pos-revolucionaria, hurgando en los acontecimientos históricos que dieron lugar a temáticas abordadas, tanto en largometrajes de ficción como en documentales.

5 El período especial en Cuba se produjo en la década de 1990, tras la caída del Campo Socialista Europeo en 1991. Unido al recrudecimiento por esos años del bloqueo económico impuesto por Estados Unidos, la isla vivió uno de los peores momentos de su historia contemporánea.

ESCENA. Revista de las artes, 2021, Vol. 81, Núm. 1 (julio-diciembre), pp. 183-206 
Historias cruzadas en noches oscuras: acercamiento crítico

Artículo a la película cubana Chamaco (2010) de Juan Carlos Cremata

No solo el cine independiente se nutrió de esta nueva realidad. También directores que producían al amparo del ICAIC se abocaron a la representación de lo social desde nuevos personajes, temas y estéticas más cercanas a los márgenes de un país en jaque económico y político. Al respecto, Pérez (2020) asegura que:

fue un suceso de tal magnitud para la Historia del país, que sus efectos modificaron la idea misma de Verdad (política, estética, ideológica) que estructuraba la vida nacional; una crisis de los discursos que se acentuaría en su diálogo con la desaparición del Socialismo Real en Europa, un hecho que puso en crisis las ideas por él privilegiadas. Esa problemática se transparentó de inmediato en el hecho filmico: pasó ella misma a producir el enunciado cinematográfico (p. 3).

Pérez pondera la realización de Video de familia (2001) de Humberto Padrón (1967) como un punto de inflexión en la cinematografía cubana, no solo por constituir una producción independiente que abrazó temáticas sociales poco exploradas hasta el momento, con lo que se forjó un espacio fuera del ICAIC, sino también por los nuevos recursos tecnológicos que suplantaron a los $35 \mathrm{~mm}$ y posibilitaron una "democratización de la producción audiovisual" en "un campo presa de múltiples restricciones económicas, de las imposiciones ideológicas del ICAIC y su criterio de creación" (Pérez, 2020, p. 5). Fue aquel un momento propicio para que voces que no habían vivido el cambio político-social de 1959 -o al menos no lo habían experimentado en su etapa adulta- encontraran un espacio dentro de la creación audiovisual ${ }^{6}$.

La escasez de recursos económicos en el país redujo sustancialmente las posibilidades de que el ICAIC asumiera el financiamiento de la producción ${ }^{7}$, por lo que en la década de 1990 se dio una apertura a las coproducciones con capital extranjero. Esta participación, en muchos casos, menguó de forma notable la calidad de los filmes, pues las contrapartes foráneas incidieron directamente en los argumentos, guiones y procesos de realización. Al decir de Álvarez (2016):

6 Sugerimos consultar el dossier "Insomnios posrevolucionarios. Agotamientos, desvíos y reescrituras en el cine cubano contemporáneo”, publicado por laFuga, núm. 24 (Invierno 2020), en el cual se amplían temáticas relacionadas con el cine cubano contemporáneo.

7 Sugerimos consultar a Kabous (2019), quien abunda sobre el sistema de financiación y distribución del cine cubano.

ESCENA. Revista de las artes, 2021, Vol. 81, Núm. 1 (julio-diciembre), pp. 183-206 
fuimos como los otros quisieron vernos... En algunas coproducciones los cubanos fueron presentados mayormente como marginales, proclives a la prostitución y asolados por una pobreza material que hacía frágiles sus principios morales y ciudadanos. El mejor ejemplo de estos resultados fue una serie de comedias que exacerbaron las reales y duras condiciones de sobrevivencia no solo de la sociedad y los cubanos, sino del propio cine. Se trataba de un hiperrealismo social que dejaba atrás la búsqueda de una estética artística (p. 98).

El hecho de que una buena parte de las coproducciones de la década de 1990 fuesen comedias en las que se hiperbolizaron las situaciones cotidianas del pueblo cubano es revelador de los tintes de hiperrealismo social al que hace referencia Álvarez (2016). Los guiones buscaron elementos del contexto y los llevaron a un tono de comedia que, en muchos casos, exageraba las verdaderas condiciones. Estas no pretendían ser una réplica exacta de la vida en la isla, sino la presentación basada en una simulación de la realidad. Ahora bien, esto no necesariamente significa que existió una búsqueda de determinada propuesta estética en torno al hiperrealismo o que los directores tuvieran intenciones particulares en el discurso como tal. Consideramos que, en estos casos, se trató de un aprovechamiento de las circunstancias sociales de producción y no precisamente de una postura estética.

Así, la pérdida de valores, la pobreza, la prostitución, la sexualidad y otros tópicos comienzan a campear por un espacio dentro de la cinematografía cubana, largometrajes que traslucen el dolor, las marcas, las heridas de una sociedad que vuelve su mirada hacia adentro, hurgando en problemas hasta entonces latentes, pero ahora en evidencia absoluta. Por su parte, Pérez (2020) plantea este fenómeno en tanto cambio de paradigma ideológico, a partir del modo en el cual los creadores estructuran sus discursos audiovisuales: "la hegemonía del discurso nacionalista empieza a languidecer, con lo que se dinamitan los signos desde los que se pensaba y representaba Cuba como comunidad imaginada" ( $p$. 4). Precisamente, porque el cine cubano ha estado intrínsecamente ligado a su realidad inmediata, a las necesidades de expresión de su gente, los directores se han apropiado de ellas para plasmarlas en una amplia gama de producciones, en años más recientes, de carácter independiente. Sin embargo, deben resaltarse aquellos aspectos positivos que trajo consigo la carencia económica gubernamental:

Al no existir la abundante subvención estatal, condicionó una mayor libertad creadora de los realizadores, ya que al buscar o recibir financiamientos fuera del ICAIC pudieron conceder más espacio dentro de las películas a sus propios criterios sobre 
Historias cruzadas en noches oscuras: acercamiento crítico

Artículo

a la película cubana Chamaco (2010) de Juan Carlos Cremata

las muy complejas dinámicas sociales de entonces, sin estar tan sujetos a las visiones oficiales. Esa libertad condicionada fue un avance en cuanto a la capacidad y diversidad de juicios que los directores pudieron impregnar a sus obras. Los límites de la censura fueron ensanchados y los cineastas cubanos pudieron expresar más abiertamente su realidad social. Los realizadores en general comenzaron a cuestionar la quimera heroica que había supuesto la revolución hasta inicio de los 90. Lo hicieron desde una percepción de desaliento donde la visión de la nación y de la sociedad en general fue adquiriendo un matiz individual; en otras palabras, la visión personal del ciudadano se fue imponiendo sobre la épica colectiva (Álvarez, 2016, p. 99).

Así, las coproducciones con empresas extranjeras permitieron, por un lado, dar continuidad a la creación cinematográfica en la isla y, por otro, diversificar las temáticas representadas. Al entrar en juego varios intereses narrativos y estéticos, las producciones realizadas en y sobre Cuba incluirían personajes de diversa procedencia, como es el caso de los españoles, según afirma Planas (2020). La historia cultural cubana ha demostrado que la relación con España tiene raíces profundas, aún en la actualidad. Por tanto, el hecho de que algunos personajes españoles aparecieran en la gran pantalla fue, quizás, una de las herramientas menos forzadas dentro de los argumentos. Para ese autor, tal recurrencia llevó a la producción cinematográfica de la isla a los premios Goya de la Academia de Cine de Madrid, España, con lo cual contribuyó a la internacionalización del cine cubano y "a cambiar las formas de diálogo con la censura a nivel local" -que imponían productoras como el ICAIC y el Instituto Cubano de Radio y Televisión-, además de establecer una distinción entre "lo que se entiende como cubano o foráneo" (Planas, 2020, pp. 1-2). Estas características continuaron permeando las producciones cinematográficas de la primera década del siglo XXI. A propósito, el crítico cubano Joel del Río (2011) asegura:

Habrá que buscar la singularidad de los nuevos, tal vez, en el tratamiento de temas raciales, sexuales, clasistas, ideológicos, existenciales y artísticos desde una óptica bastante desacostumbrada, por insolente y expedita. El cine joven cubano mantiene su carácter oxigenante, novedad de enfoque y cierta raigal inconformidad. He ahí su honra y su premio (párr. 20).

La generación de cineastas que sobresalió durante esa década ansiaba "una expresión de vanguardia" y, con ella, "desplazaron el paradigma promovido por el ICAIC y diversificaron la morfología narrativa del cine cubano", al tiempo que "han atomizado la uniformidad que venía siendo característica en el cine de la isla después de su época 
dorada" (Pérez, 2020, p. 5) ${ }^{8}$. Dentro de esa oleada, se encuentra Juan Carlos Cremata (1961), director del largometraje de ficción Chamaco (2010). Se trata de su cuarta película, concebida de forma independiente, motivo por el cual gozó de toda la libertad creativa para realizar la puesta en escena. Cremata tomó como base la obra teatral homónima del joven dramaturgo Abel González Melo (1980), una práctica que ha sido recurrente en algunas de sus más recientes películas: El premio flaco (2009) y Contigo, pan y cebolla (2012), inspiradas en clásicos homónimos del dramaturgo cubano Héctor Quintero (1942-2011). Al ser Cremata un cineasta y director teatral muy contestatario, quien gusta de llevar a sus propuestas la realidad cubana -vista desde diferentes aristas y muchas veces signada por el sarcasmo-, Chamaco se convirtió en el guion perfecto que le permitiría llevar al cine, por primera vez, algunas facetas de suma crudeza de la sociedad cubana. Aunque sus personajes, en realidad podrían habitar en cualquier ciudad del mundo. Cremata decidió emprender el proyecto contando con la voluntad desinteresada de actores, equipo técnico, músicos y demás miembros del staff, por lo que podría afirmarse que la película no contó con capital financiero, sino capital profesional.

Después de su estreno en salas de cine cubanas, Chamaco obtuvo ese año (2010) el Premio ALBA Cultural "Latinoamérica Primera Copia" del XXXII Festival Internacional del Nuevo Cine Latinoamericano, reconocimiento que precisó al ICAIC a publicarla bajo su sello al año siguiente. Además, recibió el Premio al Mejor Largometraje Internacional en el XV Festival de Cine ICARO, celebrado en la Ciudad de Guatemala, en 2012. Paralelamente, la película se ha exhibido en varias ciudades de los Estados Unidos, así como en España y otros países de Latinoamérica.

En este trabajo nos proponemos realizar un ejercicio crítico sobre la película, con el objetivo de generar otra voz a lo estudiado en torno a ella. Sin embargo, hasta el momento, no se cuenta con estudios académicos dedicados exclusivamente al filme, por lo tanto, este es un aporte distintivo dentro del canon. Las preguntas que originaron y guiarán el estudio son las siguientes: ¿qué temas sociales introduce Chamaco a la cinematografía cubana?,

8 Pérez (2020) hace referencia a la Muestra Joven, creada por el ICAIC para aquellas producciones independientes, es decir, realizadas sin financiamiento de la institución, un espacio propicio para el intercambio intelectual en torno a lo más reciente que se gestaba en el campo cinematográfico cubano (pp. 5-6). No obstante, el autor afirma que los primeros intentos de crear un cine ajeno a los predios del ICAIC se remontan a las décadas de 1970 y 1980, con "los miembros del magazine Lunes de Revolución" y el "Primer Festival de Cine Underground" (pp. 9-10).

ESCENA. Revista de las artes, 2021, Vol. 81, Núm. 1 (julio-diciembre), pp. 183-206 
Historias cruzadas en noches oscuras: acercamiento crítico

Artículo

a la película cubana Chamaco (2010) de Juan Carlos Cremata

¿cómo maneja Cremata los códigos cinematográficos a partir de una obra teatral, teniendo en cuenta la relación teatro-cine o viceversa? y ¿cuál es la construcción de sentidos desde la imagen que interesa mostrar a su director? Nos apoyamos en aquellas publicaciones que hacen referencia a la película y a la obra teatral homónima, pero también a aspectos históricos de la industria cubana del cine, el cine queer y la construcción de sentidos desde la imagen.

\section{La diversidad sexual masculina: un tema transversal en Chamaco}

El cine, en tanto lenguaje artístico y técnica capaz de retratar la vida a partir de sus coordenadas sensoriales más características, como lo son la imagen en movimiento y el sonido, ha asumido desde sus inicios el reto de plasmar aspectos complejos de la condición humana (Cruz, 2015, p. 23).

En sintonía con los diez capítulos que estructuran el texto de González Melo, la película va desarrollándose a través de nueve actos, en los que se describe -a manera de informe policial- la historia de ocho personajes, cuyas vidas se cruzan en el decurso de cuatro noches en La Habana. García (2011) asegura:

Muy propio de las estructuras de González Melo es que cada secuencia ostente una cierta unidad o autonomía, con su propio núcleo conflictivo, a la vez que se encuentra estrechamente interconectada con las demás. Se advierte una tendencia general a que los personajes vayan coincidiendo a la manera de una ronda, aparentemente desordenada, pero en realidad tramada con suma habilidad. Con frecuencia se presenta una situación en la que todos confluyen. Las acciones van entretejiéndose en función del clímax, que suele situarse hacia el final (p. 413).

Una estructura similar es asumida por Cremata en su película, con lo que ofrece la sensación inicial de escenas aisladas. Sin embargo, a medida que transcurre la película vamos estableciendo esas conexiones propias de los personajes que la habitan. Chamaco comienza con el descubrimiento de un muchacho asesinado en el Parque Central de La Habana, evento a partir del cual se desata una cadena de coincidencias que, en su totalidad, aluden y denuncian los hechos acontecidos, la corrupción y el contexto de la prostitución masculina que permanece oculto tras sus fachadas.

Karel Darín, personaje protagónico de la trama, es un muchacho del interior del país, con escasos recursos económicos, quien viaja a la capital en busca de mejoras que le permitan subsistir. Llegadas las celebraciones de fin de año, se encuentra en el parque 
con otro joven, Miguel Depás, con quien juega una partida de ajedrez en la que media una apuesta económica. El duelo termina en una riña entre ambos, donde Karel apuñala a Miguel. Una señora en condición de calle (Roberta) presencia el altercado y se queda en el lugar de los hechos, en el cual, poco después, aparece una mujer trans ${ }^{9}$ quien se dedica a la venta ambulante de flores. La señora le cuenta a esta lo sucedido. "La Chupi" -apodo en la versión cinematográfica de este último personaje- mantiene relaciones sentimentales con un policía encubierto de la zona, quien aparece en la historia en medio de la conversación que sostienen ambas.

Asustado por lo ocurrido, pero sin saber que había asesinado a su contrincante, Karel huyó del lugar y, entre los escondrijos oscuros de las calles aledañas al parque, se encuentra con un señor de unos cincuenta y tantos años de edad, quien lo seduce y convida a tener sexo en un próximo encuentro, a cambio de dinero. Saúl Alter, el policía encubierto, observó la escena anterior y llega poco después a intimidar al protagonista. Saúl, luego de haber revisado el documento de identificación del occiso, sabía que se trataba del hijo del juez Alejandro Depás, a quien acaba de ver conversando con Karel. Es este policía quien inicia la investigación acerca del reciente asesinato, razón por la cual no deja de hostigar, en adelante, al protagonista de la trama.

Luego, vemos que Karel pernocta en la propiedad de un señor mayor, homosexual, aparentemente un tío lejano, quien lo acosa, suplicándole que la forma de pago por brindarle su techo sea recibir de él recompensas mediante el contacto físico. En venganza por el constante rechazo de su sobrino, el tío realiza un simulacro de agresión para denunciarlo ante la policía y es Saúl quien atiende el caso, oportunidad que aprovecha para chantajear a Karel, al punto de obligarlo a tener sexo oral con él. A medida que van pasando las horas, durante esas noches de diciembre, la trama comienza a develarse y encontramos una relación cada vez más estrecha entre los personajes. Es entonces que conocemos acerca de un romance estable, pero no público, que mantiene Karel con Silvia, una joven médica. Es ella la única persona que le rodea con la que siente cierto equilibrio emocional, en medio de su convulsa realidad.

9 Aunque en el filme se nombra a este personaje como "travesti" y no se menciona que se trata de una mujer transsexual o transgénero, hemos decidido emplear el término "mujer trans" por ser el más adecuado en este caso. En Cuba, popularmente, suele denominarse "travesti" a todo aquel hombre que, asumiéndolo como una identidad de género o no, viste, se autopercibe y conduce como mujer. 
Historias cruzadas en noches oscuras: acercamiento crítico

Artículo

a la película cubana Chamaco (2010) de Juan Carlos Cremata

Sin embargo, una de las subtramas más crueles del filme nos revela el núcleo familiar que integran el juez y sus dos hijos. Por un lado, ella (Silvia) era la hija correcta, que había continuado sus estudios y contribuía económicamente al sustento familiar; mientras que él (Miguel) era un hijo rechazado bajo la presión constante del padre, por ser la antítesis de su hermana. Hacia el final de la película, el protagonista de la historia se percata de que el muchacho al que había asesinado en el Parque Central de La Habana era hermano de su novia e hijo de su nuevo amante-cliente, quien se lamenta por no haber propiciado en vida un acercamiento con su hijo Miguel. Es entonces que, abrumado ante la relación que existía entre todas esas personas que giraban alrededor de su vida actual, la noche en que se destinaba a tener sexo con Alejandro (el juez), Karel decide clavarse un puñal en el cuello. Así culmina la historia de Chamaco.

Como pudo apreciarse, en síntesis, se trata de una trama convulsa, susceptible de ser contada desde cualquier parte del mundo, ya que en cualquier sociedad contemporánea este tipo de situaciones pueden ser cotidianas. Entre ellos, un tema escasamente abordado en la cinematografía cubana es la prostitución masculina, uno de los ejes transversales de la película. De igual forma, es la temática gay:

Aunque con Fresa y chocolate [Tomás Gutiérrez Alea y Juan Carlos Tabío, 1994] ya apareció el tema de la homosexualidad en el cine cubano y desde entonces otros directores han rodado también obras sobre este tema, Chamaco es un paso más para crear la categoría de cine gay en Cuba (Lénárt, 2014, p. 53).

Muy probablemente, ese autor haga tal afirmación porque la homosexualidad masculina está presente en Chamaco de diferentes formas. Ciertamente, Fresa y chocolate (1994) es el filme icónico de esta temática en el país, además, por haberse rodado y expuesto en un momento en el cual la sociedad cubana aún no la había visto reflejada en la pantalla grande. Sin embargo, los personajes gays, transexuales o transgénero han sido cada vez más recurrentes desde entonces, incluso, a través de historias basadas en hechos reales que los sitúan como protagonistas. Podemos citar entre ellas Casa vieja (2010) de Lester Hamlet, Verde verde (2012) de Enrique Pineda Barnet, Vestido de novia (2014) de Marilyn Solaya, Fátima o el Parque de la Fraternidad (2014) de Jorge Perugorría y Viva (2015) de Paddy Breathnach.

No obstante, consideramos que, más allá de una categoría de cine gay en Cuba, Chamaco debería situarse dentro del pensamiento queer, ya que preconiza todo aquello 
que se aparta de la mirada heteropatriarcal y el sistema sexo-género. Pero, también aborda la distinción entre heterosexual y homosexual (igualmente, binaria), para dar cabida a otras formas de reconocer la sexualidad de las personas y la manera en la que establecen sus relaciones con otros seres humanos. Según Spargo, el término queer hace referencia a un espectro diverso de prácticas críticas y prioridades que podemos encontrar en las representaciones del deseo hacia el mismo sexo, tanto en obras artísticas como literarias, además de analizar las relaciones de poder de la sexualidad, manifiestas en los ámbitos social y político, entre otros campos de acción (citado en Castro, 2005, p. 5). Por tanto, dada la variedad de perspectivas en las cuales el cine cubano ha representado a las personas no identificadas/ bles con la binariedad de género (masculino/femenino) o aquella impuesta entre hetero y homo es que el término gay carece de espacio para otras formas de asumir y manifestar la sexualidad, entre ellas: transexual, transgénero, intersexual y bisexual, entre otras ${ }^{10}$.

Para ejemplificar cómo otras manifestaciones de la sexualidad masculina están presentes en la película que aquí analizamos y cómo cada personaje socializa su sexualidad con otros individuos tenemos que, de los cinco roles masculinos que intervienen en Chamaco (sin contar a la mujer trans), el único que no mantiene una conducta homosexual o bisexual es Miguel Depás. Por una parte, encontramos dos de los estereotipos más comunes en la construcción de la persona gay que los medios audiovisuales han ponderado desde la inclusión de este tipo de personajes: la "travesti" (La Chupi) y el hombre que se expresa con ademanes afeminados (el tío de Karel). Sin embargo, la diversidad sexual masculina trasciende en Chamaco dichas construcciones sobre "los otros gays" para incluir también varias facetas de la bisexualidad. A saber, el padre de familia (Alejandro), viudo, decidido a pagar los servicios sexuales de un hombre joven, en cuya posición vemos un desdoblamiento contrastante con el carácter rudo del hombre empeñado en mostrarse ante sus hijos con rectitud e intachable conducta ciudadana (no olvidemos su desempeño profesional como juez); el policía (Saúl) que mantiene una relación amorosa -mas no pública- con la mujer trans

\footnotetext{
${ }^{10}$ Sugerimos revisar la propuesta de Lugo (2014) respecto a "tres orientaciones principales desde las que pensar/accionar lo queer". En su segunda posibilidad, el autor incluye a personas heterosexuales, pero cuyos comportamientos no se corresponden con aquello que establece y favorece la heteronormatividad: "Io que atenta contra, o no cuadra del todo con, los paradigmas de la conyugalidad / matrimonio, la reproducción / de la familia nuclear, la heterosexualidad obligatoria, etc., y que en la medida en que se resiste a identidades esencialistas, si bien no a las identidades complejas, puede incluir gente heterosexual, entre otras" (p. 670).
} 
Historias cruzadas en noches oscuras: acercamiento crítico

Artículo

a la película cubana Chamaco (2010) de Juan Carlos Cremata

y que también chantajea sexualmente al protagonista de la historia y, finalmente, a Karel, quien mantiene una relación con Silvia, pero está dispuesto a ofrecer servicios sexuales a otros hombres a cambio de dinero.

Otra característica que atraviesa Chamaco es el ambiente marginal que abraza a cada una de las facetas de la sexualidad masculina hasta aquí comentadas. Una marginalidad entendida no solo por la presencia de conductas humanas como el chantaje, la manipulación o la prostitución, sino también mediante las acciones ocultas, arropadas por la noche (en tanto recurso visual que promueve la oscuridad en la cual se desenvuelven las interacciones sexuales). Esto además implica el miedo a ser descubierto por quienes juzgan relaciones no tradicionales, cuestionadas en su mayoría por la ley y la "moralidad social". Por tanto, la marginalidad en Chamaco debe entenderse desde dos miradas complementarias entre sí, que encuentran en el relato fílmico muchos recursos de apoyo, los cuales serán comentados más adelante.

Debemos resaltar, además, que la película no hace referencia al conflicto que supone la "salida del clóset" -típica del reconocimiento de la persona homosexual-, como sucede en Casa Vieja. Tampoco alude a los clichés amorosos construidos alrededor de una relación común entre dos personas que se aman, tal y como se presenta en Fresa y chocolate; por no mencionar la ausencia de la persona homosexual portadora de $\mathrm{VIH}$, algo común en la última década del siglo pasado, según lo expone Castro (2005) sobre el cine de aquellos tiempos y la inclusión de personajes con una orientación sexual diferente a la heteronormada. Por el contrario, Chamaco presenta esta diversidad sexual de forma cruda, directa, sin pudor, bien sea por deseo propio o signadas por la prostitución. Podríamos decir también que el filme nos presenta varias caras de la "homosexualidad [o bisexualidad] como excepción, sin cotidianidad" (Lugo, 2014, p. 673).

Por lo anterior, consideramos que Chamaco marca una ruptura en el tratamiento de la diversidad sexual masculina en el contexto cubano. Al mismo tiempo, es notable el deseo de Cremata por llevar a la gran pantalla una trama concebida originalmente para el teatro, con lo que alcanzó una audiencia mayor: historias de vida que merecen un espacio de representación como ese. Pero, también es relevante el hecho de llevar a la cinematografía cubana otra mirada de la prostitución, que tambalea el estereotipo instalado en el imaginario colectivo respecto de sí misma, delegado mayoritariamente al género femenino.

ESCENA. Revista de las artes, 2021, Vol. 81, Núm. 1 (julio-diciembre), pp. 183-206 


\section{La construcción de sentidos desde la imagen}

En las últimas décadas, el teatro cubano ha sido muy arriesgado en sus propuestas, en las cuales encontramos una alusión constante al fluir de la conciencia: psicológica, individual, social, emocional, temporal y moral. Todos estos contribuyen a la conformación de personajes y argumentos complejos, destinados a hacer un llamado a la reflexión acerca de las actitudes humanas y concientizarlas en sus diferentes aristas. La puesta en escena teatral de Chamaco, si bien constituyó un hecho destacable a favor del director Carlos Celdrán y su compañía Argos Teatro no tuvo el impacto masivo implícito en una producción cinematográfica. Llevar al séptimo arte la historia de González Melo mostraría ante el gran público no solo una realidad subyacente en la cual algunos no querían verse reflejados y otros no querían verla contada a través del celuloide, sino también el posicionamiento ideológico que planteó y defendió el director al asumir el filme. Al respecto, Zizek (2008) asegura que:

La palabra "ideología" puede designar cualquier cosa, desde una actitud contemplativa que desconoce su dependencia de la realidad social, hasta un conjunto de creencias orientadas hacia la acción, desde el medio indispensable en el que los individuos viven sus relaciones con una estructura social, hasta las ideas falsas que legitiman un poder políticamente dominante (p. 10).

Consecuente con su naturaleza oscura, consideramos que Chamaco no es un filme que esté dirigido a todo tipo de público. Si bien encontramos un fuerte compromiso con una temática de cualidad universal, que nace de una necesidad de expresión social, no está destinado ni codificado en términos del gran público, sino a aquel más avezado en determinado tipo de cine de autor, de denuncia, que compromete, que inquiere a las estructuras sociales, que pone el dedo sobre las llagas de la sociedad. Máxime, en un contexto como el cubano que, por décadas, preconizó una mirada triunfalista y de corrección política en su cinematografía.

Cremata expresa una necesidad casi visceral de realizar el filme, de un manifiesto interés personal por mostrar una realidad apenas develada, acaso por su matiz noctámbulo, clandestino y marginal. En ello, va implícito su deseo de llevar al cine cubano un rodaje que pusiera de manifiesto la temática gay (o queer), como se mencionó anteriormente. Esta aseveración muestra que, aunque el entorno social es un factor fundamental, propulsor del hecho artístico, también está dado por la individualidad creadora puesta al servicio de la necesidad per se y no precisamente como consecuencia de un deseo de expresión, 
Historias cruzadas en noches oscuras: acercamiento crítico

Artículo

a la película cubana Chamaco (2010) de Juan Carlos Cremata

basado en un fenómeno social cercano a la realidad del productor de arte. En este caso, la motivación del director podría estar matizada por la confluencia de la situación en que se produce el hecho artístico (el contexto) y el interés personal. Ambos son, pues, factores detonantes de Chamaco. Aunque pareciera que la obra está atada a su condicionamiento inmediato y que responde a una necesidad local de expresión, no es así. El filme trasciende toda frontera espacial y cultural, y se proyecta como universal y perfectamente exportable a cualquier otro paraje, ya que, como apuntamos más arriba, sus dilemas son inherentes a la condición humana. No se puede catalogar entonces como una obra que refleja únicamente lo nacional que parte de un creador situado en determinado país.

Mucho se ha debatido acerca de lo nacional en el arte. ¿Qué aspectos describen la nacionalidad de la obra artística, más aún en un mundo donde el flujo migratorio y la globalización de la cultura son categorías que atraviesan dicho proceso? Incluso, ¿hasta qué punto las obras artísticas pueden reflejar lo nacional -aun viviendo el autor en su propio país-, cuando actualmente la práctica habitual es la reelaboración de los discursos, de las estéticas, sobre la base del reciclaje cultural posmoderno? En este sentido, debemos mirar desde una perspectiva individual las diferentes expresiones artísticas, contrastando a los propios creadores, pero sin desestimar el devenir sociocultural como otro de los múltiples factores que determina la obra. Entonces, podremos comprender sus necesidades particulares para, luego, construir un discurso histórico a partir del arte. En sus disertaciones psicoanalíticas, Calabrese (1987) nos dice que Hochberg, por ejemplo:

acepta la idea de la arbitrariedad del símbolo visual..., pero la explica no como un hecho innato, sino como conclusión de un proceso de selección y combinación, según criterios de pertinencia, proceso que se desarrolla a partir de los estímulos reales provenientes de la experiencia del mundo (p. 57).

Por su parte, Álvarez (2016) plantea esta disyuntiva en el sentido de la relación cine comercial y cine cultural, en el deseo porque las nuevas generaciones de cineastas cubanos no pierdan la identidad nacional que le otorgue universalidad a sus producciones, tal y como sucedió en las décadas sucesivas al Triunfo de la Revolución Cubana. El autor prefiere pensar en la categoría de cine cubano como alternativa que trasciende al cine hecho en Cuba y se aboca a lo local, histórico, cultural y socialmente condicionado como elemento distintivo frente a la uniformidad comercial. Chamaco es, por tanto, un filme que tiene un fuerte anclaje en problemáticas y dinámicas locales, desde las cuales construye una propuesta estética propia que, por local, trasciende los marcos del cine comercial y las 
fórmulas que este supone. Ello brindó la oportunidad al director de posicionar el filme -y en particular los temas tocantes al mismo- en el debate nacional en primera instancia, a la vez que logró situarlo también internacionalmente.

\section{Del teatro al cine: concepto de la imagen}

El hecho de que el guion cinematográfico encontrara su génesis en una obra teatral y que no tomara excesivas licencias en el momento de llevarlo a la pantalla provoca que este filme logre en el espectador un ejercicio fabuloso de traslación del lenguaje eminentemente teatral al cinematográfico y viceversa. Pudiera decirse, incluso, que se funden en una misma codificación. Al respecto, Zizek (2008) asegura que "el contenido no es lo que importa, sino el modo como este contenido es funcional respecto de alguna relación de dominación social" (p. 2). En ese sentido, Chamaco es una obra que no solo se debate -como ahora- en la aludida dualidad de teatro-cine, sino que también lo hace en la dicotomía teatro-literatura. Como hemos apuntado, Cremata navega indistintamente entre uno y otro mundo, lo cual le permite desmitificar dicho traslape. Llaman la atención en el filme características sobresalientes de la obra literaria, como son la franqueza, el pesimismo y la crudeza con que aborda las múltiples temáticas que encierra su argumento -en muchas oportunidades rayando al realismo sucio-, afrontadas con total desprejuicio y sin filtros morales.

El concepto de imagen que concibió el director la convierte en una película totalmente oscura. De hecho, no contiene ninguna escena diurna, pues todo transcurre de noche o en lugares cerrados, donde la luz natural o artificial no invade el set de filmación. En consecuencia, Cremata no pretende evocar "la belleza" como paradigma estético, característica que sí consigue, por ejemplo, con el colorido y excelente trabajo de fotografía de sus anteriores filmes Viva Cuba (2005) ${ }^{11}$ o El premio flaco (2009). Precisamente, con

\footnotetext{
${ }^{11}$ Según Fernández (2020), Viva Cuba se convirtió en la primer película cubana premiada en el Festival de Cannes, en Francia. Según el autor, "a partir de ese exitoso precedente se producen un número considerable de obras centradas en las problemáticas de la niñez, hasta constituirse casi que en tendencia", entre las cuales menciona: La edad de la peseta (Pavel Giroud, 2006), Habanastation (lan Padrón, 2011), Y, sin embargo (Rudy Mora, 2011), La piscina (Carlos M. Quintela, 2011), Conducta (Ernesto Daranas, 2014), Crepúsculo (Juan Pablo Daranas, 2015), Esteban (Jonal Cosculluela, 2016) y Club de Jazz (Esteban Insausti, 2018, p. 1).
} 
Historias cruzadas en noches oscuras: acercamiento crítico

Artículo

a la película cubana Chamaco (2010) de Juan Carlos Cremata

Chamaco busca deliberadamente una imagen de baja calidad, decadente, poco iluminada y sin artificios tecnológicos. Esto va de la mano y potencia el argumento del filme, relativo a la marginalidad y la degradación social.

El constante uso de la cámara fija encuentra puntos de coexistencia con el teatro. También lo es la interacción de pocos personajes en cada escena, donde predominan los dúos, aspecto que resalta García (2011) al referirse a la dramaturgia de González Melo. Asimismo, el empleo recurrente de los planos cerrados confiere a la imagen una sensación -también generada en el espectador- de encierro, confinamiento, acorde a la situación límite en que se encuentran los personajes. A la vez, se establece cierto nivel de intimidad e implicación emocional, algo muy propio también de lo que sucede durante la representación teatral en una sala. Además, el trabajo escenográfico de Chamaco acude a espacios lúgubres, valiéndose de objetos inservibles o desechos, que evidencian la pobreza de sus convivientes y lo sórdido del entorno. Todo ese entorno obedece a la intención primigenia de su director de llevar a su máxima crudeza la historia contada, no solo basado en las claves del texto original, sino también aquellas que él concibe como apoyo paralelo desde su trabajo como cineasta. De ahí que haga confluir con muy buen tino un grupo de elementos que conectan tanto con la obra literaria, como con los referentes del teatro, esta vez resignificados en un discurso coherente y efectivo, lo que demuestra la versatilidad de Cremata para defender a toda costa la verdadera esencia de una historia.

Por una parte, el director toma esta tragedia posmoderna y realiza una puesta cinematográfica que realza la obra originalmente concebida para teatro, dotándola de la riqueza visual que se abre con las posibilidades del séptimo arte. Resulta interesante ver cómo se exponen sus recursos técnico-expresivos para potenciar las intenciones en cada corte del filme. Una puesta en escena casi documental, en la que la cámara se convierte en los ojos del espectador desde la butaca de la sala: uso de primeros planos, de una cercanía casi cómplice, el predominio de escenografías oscuras, habitaciones atestadas y lúgubres, son algunos de los recursos que explota Cremata para transportar al espectador al clima de encierro, de desesperación y de tensión que viven los personajes.

Por otra parte, posee la apoyatura de una banda sonora original compuesta por Amaury Ramírez, atinadamente resuelta, con matices muy urbanos, típicos de la noche; música noctámbula y opresiva que logra contextualizar al público en ese ambiente enrarecido y marginal de la trama. El compositor se vale de recursos instrumentales, melódicos y armónicos propios del jazz, un género de raigambre popular -rechazado en sus inicios-, 
mediante el empleo del piano, la percusión y el contrabajo como instrumentos principales, aunque pueden escucharse algunas intervenciones de las cuerdas frotadas. La música, como discurso paralelo a la imagen, apoya siempre la dinámica visual, creando atmósferas coherentes con el aspecto dramático.

Uno de los códigos que usualmente maneja Cremata en cada una de sus obras es la utilización del color rojo. Al igual que lo hace el cineasta español Pedro Almodóvar con los colores rojo y verde, por ejemplo, Cremata resalta siempre aquellos detalles que algunas escenografías hacen que nuestra atención perciba su presencia ${ }^{12}$. Resulta aún impreciso develar el significado específico de esta. No obstante, al menos en Chamaco, podemos fácilmente asociarlo a la muerte -como asesinato o suicidio-, al peligro, al deseo morboso, al sexo, contextos en los cuales siempre se hace presente.

Cremata propone en su versión cinematográfica una narrativa que se mueve constantemente en el tiempo. Las escenas, inicialmente inconexas entre sí, confluyen a medida que avanza la película hasta llegar a la escena final, clímax del filme, en el cual se cierra la dramaturgia que construye el director, se revela el hilo que une a cada subtrama y el consecuente desenlace de la historia. En este caso, el espectador puede hilvanar coherentemente las escenas, porque el ordenamiento lógico ha sido resuelto de tal forma que las subtramas y problemáticas internas de los personajes le otorguen un coherente equilibrio. Sobre este particular, Deleuze (1985) afirma que "el montaje tiene que proceder por alternancias, conflictos, resoluciones, resonancias; en suma, toda una actividad de selección y coordinación, para dar al tiempo su verdadera dimensión y al todo su consistencia" (p. 56). Por tanto, el buen montaje no solo apoya al tiempo referido en el propio discurso, sino también a la velocidad intrínseca en cada escena, el ritmo interior que mueve la película y el cierre de la historia.

Otro aspecto a destacar en este filme es su condición multimodal, por la combinación de lenguajes que utiliza para transmitir el mensaje. Esto complejiza el proceso de aprehensión del discurso, puesto que ello demanda un mayor conocimiento específico de cada terreno para que el sujeto-receptor logre decodificar oportunamente la comunicación.

12 Sugerimos consultar Sánchez-Alarcón (2008), quien amplía sobre las claves cinematográficas del cine de Almodóvar.

ESCENA. Revista de las artes, 2021, Vol. 81, Núm. 1 (julio-diciembre), pp. 183-206 
Historias cruzadas en noches oscuras: acercamiento crítico

Artículo

a la película cubana Chamaco (2010) de Juan Carlos Cremata

En una producción de este tipo, el conocimiento de las especificidades de dichos códigos habilita una mejor comprensión. No obstante, eso no significa que el filme sea ininteligible para personas no avezadas en materia cinematográfica, teatral o literaria.

Cremata seleccionó un elenco de actores y actrices donde confluyeron diversas generaciones. Si bien unos cargaban con un peso mayor dentro de la trama respecto de otros, es de señalar el equilibrio en el desempeño actoral que existió. Algunos de ellos fueron los mismos que encarnaron la puesta en escena de Argos Teatro: los jóvenes Fidel Betancourt (Karel Darín), Caleb Casas (Miguel Depás), Laura Ramos (Silvia Depás) y Alfredo Chang (en su presentación especial como "La Chupi"), quienes se unieron a consagrados artistas como Aramís Delgado (Alejandro Depás), Alina Rodríguez (Roberta), Luis Alberto García (Saúl Alter) y Pancho García (Felipe, el tío).

El director siguió, por así decirlo, una atinada estrategia de selección del elenco, donde los más jóvenes ya habían encarnado sus personajes en el teatro. Ello redundó en un trabajo depurado en el aspecto actoral y el beneplácito del público que conocía la obra desde su representación sobre las tablas. Para la elección del resto de roles, convocó a artistas de amplia popularidad y reconocimiento, lo cual, junto a su prestigio como creador fueron atractivos para un público más extendido, garante del alcance de una propuesta que representó una temática novedosa y de poca acogida en el gran público.

\section{Conclusiones preliminares}

Chamaco es un filme que revela en sí mismo el largo y complejo proceso de transformaciones que se ha producido en la industria del cine cubano en la última década del siglo XX y lo transcurrido del XXI. A pesar de haberse rodado al margen institucional y sin apoyo de alguna contraparte extranjera o privada, ha logrado el reconocimiento no solo internacional, sino también ha precisado al ICAIC a asumirla como una producción bajo su sello, tras merecer el Premio ALBA Cultural "Latinoamérica Primera Copia" del XXXII Festival Internacional del Nuevo Cine Latinoamericano (2010). Este es un patrón más o menos recurrente en las últimas décadas, en el que las limitaciones económicas para hacer cine en el país han condicionado la emergencia de productoras independientes en la isla, a la vez que han abierto la participación del capital extranjero. Esto ha dado como resultado una mayor apertura institucional a nuevos temas, que el ICAIC -en muchos casos- ha tenido que acoger 
de forma circunstancial, títulos que de otra forma jamás se habrían rodado bajo su política estatal. También, ha significado la oportunidad de un mayor acceso a la comercialización y distribución internacional.

El filme muestra la complejidad de la construcción de la sexualidad masculina en un contexto donde las duras condiciones materiales de existencia "relajan" -por así decirlolos arquetipos y prácticas construidas sobre la masculinidad. Es decir, donde hombres heterosexuales pueden sostener prácticas homosexuales o bisexuales a cambio de beneficios materiales. Es este un fenómeno que, si bien no es exclusivo del contexto cubano, se ha extendido bastante en las últimas décadas de crisis económica. En Chamaco, las representaciones de la sexualidad masculina van más allá del estereotipo del hombre gay, pues varios de sus personajes manifiestan facetas totalmente distintas y desmarcadas de otros arquetipos ponderados en filmes cubanos anteriores. De ahí que propusimos analizarlo desde la perspectiva queer.

El director lleva al cine cubano una propuesta que evidencia, por una parte, la diversidad sexual masculina, pero, sobre todo, muestra problemáticas de otra índole que subyacen en el filme. No se trata solamente de que la mayor parte de los personajes se relacionen a partir de un vínculo sexual, afectivo o transaccional, sino que connota un grupo de formas de relacionamiento social en un ámbito de decadencia, carencia material y degradación social. Consideramos que ahí estriba la intensión de Cremata: utilizar el filme como un medio de denuncia de las duras condiciones de existencia de un importante sector de la sociedad cubana y los escarceos para sobrevivir.

Chamaco es un filme pletórico de simbolismos que Cremata maneja airosamente. Sin embargo, donde verdaderamente debemos resaltar el depurado manejo de lo simbólico es en la apropiación que realiza de los códigos y la ideología del mundo marginal, los cuales operan de forma certera y con plena consciencia de los resortes artísticos para provocar la identificación de los públicos. Esta suerte de thriller oscuro se nos presenta con aires novedosos tanto para el cine como para el teatro. Por un lado, el filme apuesta por mantenerse fiel al guion de teatro. Lo lleva a la gran pantalla valiéndose de un recurso que goza de cierta lozanía dentro del cine del siglo XXI: la difuminación de los contornos de un arte respecto del otro, creando nuevos lenguajes híbridos -en este caso del cine y el teatro-, lo cual es una práctica propia de la creación posmoderna. Por otro lado, el texto de la obra de teatro supone un rompimiento con los códigos del drama más clásico, con pinceladas 
Historias cruzadas en noches oscuras: acercamiento crítico

Artículo

a la película cubana Chamaco (2010) de Juan Carlos Cremata

de realismo sucio que, aunque es una corriente de las letras de finales del siglo XX e inicios del XXI, es tomada como derrotero en la constitución de la obra, lo que la convierte en una creación de su tiempo.

Confluyen en la película varios elementos que contribuyen a completar la experiencia para el espectador. Así, música, locaciones, escenografía, ambientación, uso del color, iluminación, ritmo y edición se articulan para brindar una experiencia sensorial acorde al carácter de la obra primigenia. Cremata logra, de forma acertada, la atmósfera sórdida que el texto literario sugiere. No teme que sean visibles las referencias al teatro, por el contrario, se apropia del lenguaje teatral y lo transporta al cine efectivamente.

Cabe aquí llamar la atención sobre un aspecto que no hace más que demostrar el fuerte vínculo de los cineastas cubanos con los tiempos en que se produce: su fuerte compromiso con la progresión social, con el reflejo de las pequeñas y grandes historias de lo cotidiano, lo cual dota de fuerza y originalidad al celuloide en Cuba. Un cine que hoy se identifica con las principales demandas de la sociedad y es vitrina de su realidad inmediata, codificada en términos comunes con sus públicos meta. Este es un principio sine qua non para que se produzca un efectivo proceso de codificación por parte del director-encargado de concretar y conectar en una obra final las muchas partes que componen el todo-, quien debe trasladar esos códigos lingüísticos -en este caso en imágenes- al público, encargado de decodificarlos sobre la base del reconocimiento de un lenguaje común.

Para comprender de una mejor manera el proceso de codificación que se inicia con la producción de símbolos que hace el director, es importante exponer que los creadores establecen una particular manera de interactuar con el entorno. Su sensibilidad les permite aprehender con mayor facilidad todo aquello que a la vista de otros no es significante y, debido de ello, poseen la facilidad para realizar la producción de significados, la síntesis de ideas, juicios, sensaciones. Sucede así que aquellas personas, cuya creatividad les permite establecer esa percepción diferente para con la naturaleza y demás expresiones artísticas, logran captar de mejor manera los procesos y traducirlos en obras concretas, codificadas, portadoras de un sistema de símbolos que sintetizan aquello que el creador fue capaz de aprehender en su interacción con el fenómeno. De ahí que la riqueza de Chamaco sea la multiplicidad de interpretaciones que pueden extraerse de los sucesos que narra, debido a la perspicacia, primeramente, de su escritor/dramaturgo y, después, del director en su versión cinematográfica, porque la realidad que aborda resulta tremendamente compleja y rica en significados.

ESCENA. Revista de las artes, 2021, Vol. 81, Núm. 1 (julio-diciembre), pp. 183-206 
Es Chamaco un filme necesario, revelador, que viene a incorporar franqueza y desprejuicio a la filmografía cubana, a mostrarnos una porción obnubilada de la sociedad, a la que no nos asomamos por el riesgo que ello implica en todos los órdenes. Queda entonces la esperanza de que el cine cubano continúe abordando temáticas poco exploradas, pero no por ello ausentes de una realidad social diversa, que se complejiza y muestra otras caras a tenor con las necesidades cotidianas de los habitantes de la isla. La historia de Cuba nunca ha sido llana, pues siempre ha estado signada por la pugna, las diferencias, las luchas de clase y, por tanto, de poder. Sin embargo, una de las cualidades más sobresalientes del cubano -si cabe aquí el término simbólico- ha sido su creatividad, la cual se ha visto superada a sí misma a partir de las adversidades sociales. Ojalá sea siempre ese optimismo creativo el que prevalezca, aun cuando brote de un entorno social no exento de cierto pesimismo colectivo, pues muchas obras humanas valiosas han surgido de tiempos adversos.

\section{Referencias}

Álvarez, A. (2016). Retrospectiva histórica del cine cubano (1959-2015). Revista Estudios del Desarrollo Social: Cuba y América Latina, 4(2), 91-108.

Calabrese, O. (1987). El lenguaje del arte. Barcelona: Editorial Paidós.

Castro, M. (2005). El cine contemporáneo y la teoría queer. Butaca. Revista del Cine Arte del Centro Cultural San Marcos, 7(18), 1-10. Recuperado de https://www.academia. edu/7266980/El_cine_contemporáneo_y_la_teor\%C3\%ADa_queer..

Cruz, A. (2015). El cine como espejo de la crisis espiritual posmoderna. ESCENA. Revista de las artes, 74(2), 21-36. Recuperado de https://revistas.ucr.ac.cr/index.php/escena/ article/view/21159/21361

Deleuze, G. (1985). La imagen-tiempo. Estudios sobre cine 2. Barcelona: Editorial Paidós.

Del Río, J. (2011). La Muestra vive pendiente del horizonte. Cinémas d'Amérique latine, 19, 120-126. doi.org/10.4000/cinelatino.1143

Fernández, H. (2020). Niñez, educación y sociedad en el cine cubano contemporáneo. LaFuga, 24, 1-10. Recuperado de https://lafuga.cl/ninez-educacion-y-sociedad-en-el-cine-cubano-contemporaneo/1007

García, J. L. (2011). Análisis de la dramaturgia cubana actual. Ediciones Alarcos. 
Historias cruzadas en noches oscuras: acercamiento crítico

Kabous, M. (2019). ¿Cómo entender el sistema de financiación del cine cubano y no morir en el intento? Archivos de la filmoteca, 76, 111-124.

laFuga. (Invierno 2020). Dossier "Insomnios posrevolucionarios. Agotamientos, desvíos y reescrituras en el cine cubano contemporáneo". laFuga, (24). Recuperado de https:// lafuga.cl/dossier/insomnios-posrevolucionarios/26/

Lénárt, A. (2014). Continuidad y cambio en el cine cubano contemporáneo. Belvedere Meridionale, 26(2), 48-56.

Lugo, D. (2014). Fortunas y adversidades del revisionismo: cine queer y Contracorriente. Estudios Feministas, Florianópolis, 22(2), 667-674.

Pérez, A. (2020). Políticas de la transición. Estética audiovisual y cambio de siglo (cine cubano, 1990-2020). LaFuga, 24, 1-11. Recuperado de https://lafuga.cl/politicas-de-la-transicion $/ 1006$

Planas, J. (2020). El monopolio de lo cubano en el cine contemporáneo. ¿De dónde vienen las coproducciones como Regreso a Ítaca? LaFuga, 24, 1-8. Recuperado de https:// lafuga.cl/el-monopolio-de-lo-cubano-en-el-cine-contemporaneo/1008

Ramos, J. (2013). Las paradojas del cine independiente en Cuba: entrevistas a Fernando Pérez, Dean Luis Reyes y Claudia Calviño. Imagofagia, 8, 1-61. Recuperado de http:// www.asaeca.org/imagofagia/index.php/imagofagia/article/view/439/377

Sánchez-Alarcón, M. (2008). El color del deseo que todo lo transforma: claves cinematográficas y matices culturales en el cine de Pedro Almodóvar. Palabra Clave, 11(2), 327-342.

Zizek, S. (2008). Ideología. Un mapa de la cuestión. Buenos Aires: Fondo de Cultura Económica de Argentina. 